\title{
ARQUÉTIPO PARA USO DO FACEBOOK COMO AMBIENTE DE APOIO AO PROCESSO ENSINO-APRENDIZAGEM
}

\author{
RIBEIRÃO PRETO/SP MAIO/2018
Mariana Rodrigues Lima - UNAERP - marigamarlima@hotmail.com
Edilson Carlos Caritá - UNAERP - ecarita@unaerp.br \\ Tipo: Investigação Científica (IC) \\ Natureza: Relatório Final de Pesquisa \\ Categoria: Métodos e Tecnologias \\ Setor Educacional: EDUCAÇÃO SUPERIOR
}

\begin{abstract}
RESUMO
Este estudo tem como objetivo elaborar um arquétipo para o uso do Facebook como ambiente de apoio ao processo ensino-aprendizagem de estudantes do ensino superior da área de Exatas. Trata-se de um estudo exploratório-descritivo com abordagem qualitativa. $O$ arquétipo foi elaborado considerando a experiência dos autores em processos de ensino-aprendizagem, vivência dos mesmos como professores e tutores de cursos na modalidade semipresencial e Educação a Distância (EAD), bem como boas práticas encontradas na literatura. Para a validação do arquétipo foi realizada uma entrevista por meio de grupo focal com uma amostra intencional (professores da disciplina Laboratório de Programação I - disciplina que pertence ao núcleo comum dos cursos de Exatas de uma Universidade privada do interior paulista). Os relatos dos professores foram anotados em formato eletrônico e para análise dos comentários utilizou-se a metodologia de análise de conteúdo. Os comentários dos docentes evidenciaram que há coerência lógica e metodológica no arquétipo e sugeriram algumas melhorias, sendo que a maioria foi incorporada na versão final do arquétipo, que contempla sete etapas: criação do grupo na rede social Facebook; definição de um monitor para auxiliar na postagem dos conteúdos; reuniões com os docentes para definição dos conteúdos que serão discutidos na rede social; divulgação da página para os alunos matriculados na disciplina; cadastro dos participantes no grupo criado no Facebook; disponibilização de conteúdo e gerenciamento do grupo; avaliação da motivação e do aproveitamento didático-pedagógico dos alunos com o uso do Facebook. Portanto, é possível inferir que a implantação de um grupo no Facebook de acordo com o arquétipo proposto propiciará aos alunos da disciplina a oferta de mais um recurso didático-pedagógico, explorando os estilos de aprendizagem dos estudantes, criando outra ferramenta para apoiar os envolvidos no processo ensino-aprendizagem.
\end{abstract}

Palavras-chave: Processo Ensino-aprendizagem. Tecnologia da Informação e Comunicação. Facebook. 


\section{INTRODUÇÃo}

Contemporaneamente, observa-se que a Tecnologia da Informação e Comunicação (TIC) tem sido uma grande aliada no processo ensino-aprendizagem e os professores precisam utilizá-la no cotidiano educacional, principalmente, como recurso didáticopedagógico para motivar os alunos. Por meio de atividades interativas, é possível inovar o processo ensino-aprendizagem, propiciando assim, recursos didático-pedagógicos e experiências de aprendizagem atrativos que despertem no estudante 0 interesse em aprender a aprender.

A realidade é que estamos em pleno processo de construção de uma sociedade tecnológica digital global, que se configura como uma sociedade profundamente, dinâmica e comunicativa (comunicacional/midiática), com novas linguagens, novos códigos, novas condutas, novos costumes e novos valores (LUZZI, 2007, p. 19).

Muitas são as ferramentas que podem contribuir no processo ensino-aprendizagem, possibilitando além da geração de dados e informações, uma forma eficiente e dinâmica de compartilhamento e manutenção das relações. O conhecimento é um processo que envolve a construção de novos valores, novas condutas e muitas vezes a desconstrução de paradigmas, e a TIC apresenta-se como facilitadora neste processo de adquirir e disponibilizar novas maneiras de aprendizagem.

Para Freire (1996), ensinar não deve ser visto como um processo de transferência de conhecimento em que o professor transfere o que sabe ao aluno, que absorve passivamente o que lhe é apresentado. Ensinar é criar possibilidades para a construção do conhecimento em conjunto, em que alunos e professores são indivíduos ativos e participantes de um processo que sempre estará inacabado, podendo sempre se acrescentar algo novo.

O papel do professor é guiar o aluno na busca do conhecimento, compartilhando informações e saberes e estimulando os estudantes a fazerem o mesmo. $O$ acadêmico deve ser desafiado a aprimorar e desenvolver habilidades, pensando sempre numa maneira prática de aplicar na vida profissional e pessoal o que aprende na sala de aula e fora dela.

Quando falamos em troca de informações, conectividade e relações interpessoais, logo pensamos nas redes sociais, pois a maioria de nós acessa redes de contato online, seja para trabalho, estudo ou lazer. 
As redes sociais conectam o mundo se valendo da globalização e da necessidade humana de viver em grupo e comunicar-se. A redes sociais podem e devem ser utilizadas no contexto didático-pedagógico, pois possuem uma linguagem autônoma e construtivista, em que o aluno procura o que deseja, estabelecendo relações, comportamentos e obtendo benefícios (VIVES, 2011).

Em tempos de constantes e distintas utilizações das mídias sociais, é necessário pensarmos sobre as diversas possibilidades de inovação no ensino e de como essas mídias podem ser utilizadas e aproveitadas no contexto educacional.

Estimulando novas formas de acesso à informação por meio da TIC, pode-se potencializar o processo ensino-aprendizagem, tornar o conteúdo acadêmico mais atrativo e aproximar professores e alunos durante todo o processo de construção mútua do conhecimento.

O objetivo do estudo é elaborar um arquétipo para o uso do Facebook como ambiente de apoio ao processo de ensino aprendizagem de estudantes do ensino superior da área de Exatas.

\section{REVISÃO DE LITERATURA}

Em tempos de tantas mídias e redes sociais são necessários questionamentos sobre as diversas possibilidades de inovação no ensino e de como as mídias e as redes sociais podem se tornar aliadas do ato de ensinar.

Com a democratização do acesso à tecnologia, surgem novas possibilidades de estratégias de ensino, por meio de trocas interativas entre alunos, professores e tecnologia, promovendo uma experiência positiva nos relacionamentos interpessoais. As redes têm sido muito pesquisadas na área acadêmica, especialmente, como ferramenta pedagógica, por possibilitarem a interação (trabalho compartilhado), a interatividade (interação por meio da Internet) e a construção colaborativa. É imprescindível que os professores busquem novas estratégias e ferramentas de ensino, e neste contexto, podemos encontrar muitas possibilidades no ciberespaço (VAGULA, 2014).

A função da educação não é o simples acesso à informação, mas a construção de conhecimento a partir da informação, e em seu sentido mais amplo, a transformação do conhecimento em sabedoria, no fortalecimento de sua interrelação com a realidade 
cotidiana e sua utilização nas escolhas feitas na vida diária (MACHADO; SILVA, 2004, p. $69)$.

A escola deve proporcionar espaço para a comunicação, deve trazer o diálogo de ideias, realidades e personificação dos sujeitos, de modo que cada um contribua de forma significativa no processo de construção de uma nova sociedade. Ao se utilizarem das tecnologias e redes sociais, os docentes podem conhecer seus alunos, saber seus interesses nas redes sociais e os movimentos aos quais os mesmos pertencem, ao invés de utilizarem as tecnologias apenas como veículos de transmissão do conhecimento, os professores fariam suas práticas de forma invertida, tentando usar as mídias e tecnologias como mecanismo de manifestação e divulgação dos grupos e culturas pertencentes ao universo escolar e não mais como apenas recurso didáticopedagógico restrito a transposição de uma ou mais disciplinas e seus conteúdos (OLIVEIRA, 2015).

O Facebook é uma rede social muito utilizada e possui diversas potencialidades educativas que podem contribuir no processo ensino-aprendizagem, desde que utilizada e conduzida de forma adequada. O professor pode aproveitar do interesse e da familiaridade que os alunos têm com esta rede social para desenvolver conteúdos relacionados com sua disciplina. Para que haja sucesso nesse processo, é necessário que o professor acompanhe o desenvolvimento dos alunos, faça mediações da aprendizagem e mantenha o foco dos alunos no conteúdo que deseja tratar (MATOS; FERREIRA, 2014).

O processo educacional tem um longo caminho a percorrer, porém o uso das redes sociais e a implantação de metodologias que utilizam recursos tecnológicos tem contribuído para uma melhoria na relação de aprendizagem e aproximação entre o professor e seus alunos, além de demonstrar que as construções de saberes iniciadas na sala de aula podem continuar seu processo de construção e serem compartilhadas em rede. As discussões permanecem em pauta na página do Facebook, oportunizando a participação e colaboração de todos (OLIVEIRA, 2015).

\section{METODOLOGIA}

Trata-se de estudo de caráter exploratório-descritivo com abordagem qualitativa. Segundo Barros e Lehfeld (2007), na pesquisa descritiva não há interferência do pesquisador, que somente descreve o que foi pesquisado, procurando descobrir a 
frequência com que ocorre um determinado fenômeno, sua natureza, características, causas, relações e conexões com outros fenômenos e de acordo com Gil (2007), na pesquisa exploratória, objetiva-se obter maior familiaridade com o problema proposto, tornando-o mais explícito ou construindo hipóteses, que pode envolver levantamento bibliográfico, entrevistas ou análises de exemplos que facilitem a compreensão.

Goldenberg (1997) afirma que a pesquisa qualitativa não se preocupa com a representação numérica, mas com a compreensão de um grupo. Nesse tipo de pesquisa, o pesquisador não deve fazer julgamentos, nem permitir que suas ideias contaminem a pesquisa.

O arquétipo foi elaborado considerando a experiência dos autores do estudo em processos ensino-aprendizagem, a vivência dos mesmos como professores e tutores de cursos na modalidade semipresencial e Educação a Distância (EAD), bem como boas práticas encontradas na literatura.

Para a validação do arquétipo foi realizada uma entrevista por meio de grupo focal com uma amostra intencional (professores da disciplina Laboratório de Programação I disciplina que pertence ao núcleo comum dos cursos de Exatas de uma Universidade privada do interior paulista). Os relatos dos professores foram anotados em formato eletrônico e para análise dos comentários utilizou-se a metodologia de análise de conteúdo.

Cabe esclarecer que de acordo com Yin (2016), o objetivo da entrevista por meio de grupo focal é reunir indivíduos que presumivelmente compartilham algumas opiniões comuns. A amostragem intencional foi adotada, pois segundo lacobucci e Churchill Junir (2018), ela preconiza que a amostra poderá oferecer as contribuições solicitadas e de acordo com Campos (2004, p. 611), a análise de conteúdo, pode ser compreendida como um conjunto de técnicas de pesquisa cujo objetivo é a busca do sentido ou dos sentidos de um documento.

\section{RESULTADOS}

Para a análise qualitativa usou-se a metodologia descrita por Freire (1990), sendo que, após a leitura dos apontamentos dos entrevistados no grupo focal, foram feitas as categorizações das respostas e, posteriormente, o agrupamento em temas geradores. Os temas geradores encontrados foram: lógica e coerência didático-pedagógica, 
inclusão de novas etapas e ajustes nas orientações do arquétipo.

Como referência à categoria lógica e coerência podemos citar o seguinte comentário: "é importante a elaboração de um roteiro/modelo para uso de ferramenta computacionais, pois assim, o docente tem uma referência para utilizar o Facebook no processo de ensino-aprendizagem, o arquétipo propõe a discussão dos conteúdos entre o professor, o estudante e um monitor, o que já ocorre em um ambiente presencial, assim é coerente que esses atores do processo de ensino-aprendizagem possam estar presente em um contexto mediado por tecnologia".

Em relação a categoria inclusão de novas etapas, ela foi identificada, em virtude da sugestão de inserção de outras três categorias por um dos participantes do grupo focal, sendo: "incluiria uma 7a ou complementaria a sexta. Acrescentaria discussão de provas e projetos passados em sala de aula; uma $8^{\underline{a}}$ seria a criação de um grupo apenas com os professores, monitores e autores do projeto para aproximar e discutir o andamento e alinhamento estratégico do grupo com os objetivos perante os alunos e $9^{\underline{a}}$ alinhar com os professores da disciplina alguma estratégia para medir a percepção do impacto da ferramenta com o desenvolvimento das habilidades dos alunos em sala".

Essa categoria resultou em alterações no arquétipo, foi incorporada na descrição da $6^{\underline{a}}$ etapa, a recomendação referente a discussão de provas e atividades dadas em sala de aula e a criação da etapa de implementar ferramenta de percepção sobre o impacto do uso do Facebook no processo ensino-aprendizagem.

Para representar a categoria ajustes nas orientações do arquétipo apresentamos as seguintes falas:

- "considerar o uso de um formulário on-line para que os alunos possam fornecer os dados. as "listas" passadas durante as aulas podem dificultar a compreensão. O endereço do formulário poderia ser divulgado já nas primeiras semanas";

- "a postagem de algumas soluções comentadas, após um tempo da postagem do exercício, poderia aumentar o interesse deles pelo processo, embora em alguns casos (talvez perdidos) possa desestimular a busca pela solução antes de olhar a solução postada";

- "... interessante se ela fosse menos voltada a "postar" códigos e soluções e mais voltada a discussão dos problemas e raciocínio lógico de maneira a ajudar o aluno a chegar na solução, e não "entregá-la de bandeja". Pois a ferramenta pode acabar se tornando um lugar fácil para conseguir soluções de problemas deixados pelos professores em sala, não deixando muito espaço para instigar o 
aprendizado e desenvolvimento de raciocínio, se tornando apenas um lugar pra fazer copy/paste de maneira bem específica. Isso exigiria apenas um pequeno planejamento junto aos monitores/moderadores do grupo".

Os comentários da categoria ajustes nas orientações do arquétipo também foram utilizados para realização de atualizações no arquétipo proposto.

O arquétipo elaborado considerando as recomendações do grupo focal contempla 0 desenvolvimento de sete etapas, sendo:

- 1 etapa - Criação do grupo na rede social Facebook - criar e configurar na página do Facebook um grupo fechado, onde somente pessoas que fazem parte dos contatos do administrador do grupo poderão ser inseridas como integrantes do grupo.

- $2^{\mathbf{a}}$ etapa - Definição de um monitor para auxiliar na postagem dos conteúdos estabelecer um monitor (aluno que já tenha cursado a disciplina com bom desempenho) para auxiliar na postagem dos conteúdos, correção das atividades propostas e saneamento de dúvidas dos alunos.

- 3a etapa - Reuniões com os docentes para definição dos conteúdos que serão discutidos na rede social - entrar em contato com os professores da disciplina, apresentar os objetivos e a metodologia da proposta para os mesmos e solicitar o apoio pedagógico para que os conteúdos a serem postados na rede social sejam compatíveis aos ministrados em sala de aula, e assim, contribuir para o processo ensino-aprendizagem.

- 4a etapa - Divulgação da página para os alunos matriculados na disciplina implementação de formulário on-line para que os alunos possam fornecer os dados para, posteriormente, inseri-los no grupo; visitas nas salas de aula para apresentação do projeto aos alunos e divulgação do endereço do formulário eletrônico para envio dos dados e anotação dos nomes para cadastra-los no grupo. Os mesmos deverão ser informados de que a participação é voluntária e que o objetivo do grupo é auxiliá-lo no processo ensino-aprendizagem. Os alunos poderão inserir e sugerir conteúdos, fazer comentários, sanar dúvidas e interagir com todos os participantes do grupo.

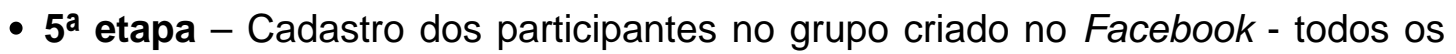
alunos que fornecerem seus dados devem ser convidados pelo administrador do grupo, e, após aceitarem os "convites de amizade", devem ser inseridos no grupo criado no Facebook.

- 6a etapa - Disponibilização de conteúdo e gerenciamento do grupo periodicamente deverão ser inseridos conteúdos e atividades para os membros 
do grupo, contudo, os acessos deverão ser acompanhados diariamente, para inserção de novos participantes que aceitarem gradativamente os convites, responder dúvidas, colocar correções e novas atividades. Discutir as provas realizadas pelos alunos e apresentar resolução comentada das atividades colocadas no grupo, bem como algumas dadas em sala de aula. Os alunos serão incentivados a interagirem, postarem conteúdos e sanarem suas dúvidas.

- 7ª etapa - Avaliação da motivação e do aproveitamento didático-pedagógico dos alunos com o uso do Facebook - definir e implementar ferramenta para análise da percepção sobre o impacto do uso do Facebook no processo ensinoaprendizagem.

Houve reflexão sobre a qualidade dos comentários e conteúdos postados e sobre seus direitos autorias, contudo, não evidenciamos como uma categoria. Mas, essa preocupação já foi mitigada no arquétipo, pois a utilização do Facebook como ferramenta de apoio ao processo ensino-aprendizagem será acompanhada por docente que ministra a disciplina, bem como por um monitor.

\section{CONSIDERAÇÕES FINAIS}

A maioria dos docentes que participaram do grupo focal expressou apoio ao uso da rede social Facebook como ferramenta de apoio ao processo ensino-aprendizagem. Este estudo contempla orientações para implantação de mais um recurso didáticopedagógico que poderá auxiliar os docentes a reforçam conteúdos iniciados em sala de aula ou em Ambientes Virtuais de Aprendizagem (AVA). Trata-se de uma ferramenta de apoio que deverá ser acompanhada pelos docentes para que os conteúdos ofertados no Facebook estejam de acordo com o plano de ensino da disciplina.

Considerando o contexto dos jovens com as tecnologias, essencialmente, aquelas que promovem interatividade, em que a sociedade contemporânea está inserida, acredita-se que o Facebook pode ser uma importante ferramenta no processo ensinoaprendizagem.

Portanto, é possível inferir que a implantação de um grupo no Facebook de acordo com o arquétipo proposto propiciará aos alunos da disciplina a oferta de mais um recurso didático-pedagógico, explorando os estilos de aprendizagem dos estudantes, criando outra ferramenta para apoiar os envolvidos no processo ensino-aprendizagem. 


\section{REFERÊNCIAS BIBLIOGRÁFICAS}

BARROS, A. J. P.; LEHFELD, N. A. S. Fundamentos de Metodologia Científica. 3. ed. São Paulo: Pearson Prentice Hall, 2007.

CAMPOS, C. J. G. Método de Análise de Conteúdo: ferramenta para a análise de dados qualitativos no campo da saúde. Revista Brasileira de Enfermagem, Distrito Federal, v. 57, n. 5, p. 611-4, set/out 2004.

FREIRE, P. Criando métodos de pesquisa alternativa: aprendendo a fazê-la melhor através da ação. In: BRANDÃO, C. R. Pesquisa participante. São Paulo: Brasiliense, 1990. P. 34-37.

FREIRE, P. Pedagogia da autonomia: Saberes necessários à prática educativa. São Paulo: Paz e Terra, 1996.

GIL, A. C. Como elaborar projetos de pesquisa. 4. ed. São Paulo: Atlas, 2007.

GOLDENBERG, M. A arte de pesquisar. Rio de Janeiro: Record, 1997.

IACOBUCCI, D.; CHURCHILL JUNIOR, G. A. Marketing Research: methodological foundations. $12^{\mathrm{a}}$ ed. North Charleston, South Carolina: Createspace Independent Publishing Platform, 2018.

LUZZI, D. A. O papel da educação a distância na mudança de paradigma educativo: da visão dicotômica ao continuum educativo. 2007. 400p. Tese Doutorado em Educação - Faculdade de Educação/USP, São Paulo (SP), 2007.

MACHADO, C.; SILVA, M. C. Pedagogia Levada a Sério. Rio de Janeiro: Editora Wak, 2004.

MATOS, E. L. M.; FERREIRA, J. L. Parte 2 - Facebook: usos no ensino superior e na formação continuada de professores. In: PORTO, C.; SANTOS, E. orgs. Facebook e educação: publicar, curtir, compartilhar [online]. Campina Grande: EDUEPB, 2014, p. 387-402, 2014.2 Disponível em: $<$ http://books.scielo.org/id/c3h5q/pdf/porto-9788578792831-22.pdf>. Acesso em 25 abr. 2018. 
OLIVEIRA, A. P. S. C. O uso do Facebook como Instrumento de Aprendizagem e Produção do Conhecimento no Curso de Formação de Professores. Anais do 21을 Congresso Internacional ABED de Educação a Distância. Bento Gonçalves, 2015. Disponível em: <http://www.abed.org.br/congresso2015/anais/pdf/BD_101.pdf>. Acesso em: 20 abr. 2018.

VAGULA, E. Redes sociais e colaboração: o uso do Facebook como ferramenta de aprendizagem no Parfor. X ANPED Sul. Florianópolis/SC, 26 a 29 de outubro de 2014.

VIVES, F. O medo de olhar para frente. Atualidades em Sala de Aula: cartas na escola, no 56, maio de 2011, p 14-17. Disponível em: $<$ https://www.cartacapital.com.br/educacao/o-medo-de-olhar-para-a-frente>. Acesso em 25 abr. 2018.

YIN, R. K. Pesquisa Qualitativa do início ao fim. Porto Alegre: Penso, 2016. 